\title{
EMBRACING WATER-SMART AGRICULTURE FOR OPTIMAL AGRICULTURAL PRODUCTION IN SELECTED AREAS OF BUSHBUCKRIDGE, SOUTH AFRICA
}

\author{
Ndlovu SM*, Agholor AI and Sithole MZ \\ Faculty of Agricultural and Natural Sciences, School of Agricultural Sciences, University \\ of Mpumalanga, South Africa
}

\begin{abstract}
Agriculture plays an important role for income generation, economic growth, and employment for majority of people. Agricultural production has become the very means of alleviating poverty. In pursuit to meet the growing demand for food to sustain the ever-growing population, the need to salvage farming and farm productions from extreme climate events using water smart practices remains paramount. The conservation of water resources for a water-scare country, such as South Africa, is important for agricultural development. Water-smart agriculture aims at addressing issues associated with water availability, water use efficiencies as well as water conservation for optimal production. The study was conducted in Chochocho, Bushbuckridge Local Municipality, South Africa. The aim of the study was to examine the adoption of water smart agriculture, and to determine the water use efficient practices employed by farmers in the study area. Random sampling method was employed, and data was collected using structured and semistructured questionnaires as well as focus group discussion. Furthermore, the descriptive and inferential statistics were used to explain responses from respondents and the Statistical Package for Social Sciences (SPSS version 27) software was used for the analysis. The study found that farmers' adoption of water smart agriculture practices was hinged on several heterogeneous variables. The study recommends amongst others, the need to conserve water for agricultural production, and water infrastructural development for local food security must be improved. Additionally, water demand and supply management issues must be addressed.
\end{abstract}

Keywords: Adoption, Water Smart Agriculture, farmers, behaviour, climate change, productivity

\section{Introduction}

The change in climate is one of the most critical problems confronting the world today. It does not only affect the agricultural sector, but it affects all other sectors, and has caused a lot of damage, and impacted many lives, namely: the human, plants, and animals (Prakash and Srivastava, 2019; Lacetera, 2019). Climate change is defined in many different ways by different authors, Stillman (2014), characterizes environmental change as a change in an area's standard climate designs. This could be as a result of an adjustment of the measure of downpour that an area normally gets per year. It could, likewise be an adjustment of an area's standard temperature for a month or season (Ahmed Khan and Nawaz, 2020). Environmental change is also known as a variety in the world's temperature. It is also referred to as a shift in where rain and snow normally fall on earth. Climate change emanates from several factors, which includes: volcanic eruption, garbage, permafrost, natural gas drilling, oil 
drilling, deforestation, fertilizers, transportation, farming, and power plants (Kelly, 2019; Sithole and Agholor, 2021). Furthermore, there are effects of climate change which streamflow timing changes, and reduces water supplies for competing demands. Major threats to water availability include an ascent in ocean level, soil and water disintegration, and flood. Furthermore, increased wildfires, insect outbreaks, and tree diseases are all contributing to widespread forest destruction (IPCC, 2007). These further contributes not only to climate change and water availability, but also deforestation.

The clearing id forests and the change in climate leads to reduced availability of water across the world. Significantly, approximately $70 \%$ of the world's water is used for agricultural purposes (FAO, 2013). However, water is progressively scarcer, due to the different demands from other sectors, such as the construction and mining sectors (Mekonnen and Hoekstra, 2016). The change of climatic patterns results in the reduction of water sources across the world. Consequently, it is of paramount importance that water is used more considerately. That is, a number of water conservation approaches must be employed both in the agricultural and non-farming sectors. Water-Smart Agriculture (WaSA) approaches assists to conserve the readily available water, for use in the agricultural sector and other economic sectors. Contemporary studies have shown that farming feeds millions of people in the world (Dey and Mukherjee, 2019). However, farmer knowledge and techniques to conserving and saving soil moisture and rain water harvesting during rainfall seasons for future use remains low (Greyling, 2015; Parry, et al., 2015). Amundson; Berhe; Hopmans; Olson; Sztein; Sparks (2015) defines WaSA as the integration of many best water usage techniques with sustainable, soil improvement, crop, and ecosystem management for resilient and effective farming. Moreover, WaSA comes with several objectives, namely: to increase crop and farm productivity, to enhanced farming resilience, and to reduce Chlorofluorocarbons' emissions.

The adoption of WaSA practices entails hands-on training and continuous capacity building for different departments namely: extension agents, producers, and technicians. Studies suggests that Water-Smart Agriculture and Climate-smart Agriculture (CSA) are partnered concepts with similar objectives (FAO, 2013). Significantly, most studies recognize WaSA as the means to achieving Climate-Smart Agriculture (FAO, 2014; Ghosh, et al., 2019; FAO, 2013).

\section{Problem statement of the study}

Climate change has become one of the biggest issues faced worldwide, it does not only affect plants and animals, but also causes serious diseases that affect human health. Contemporary studies suggest that a few regions in Africa are in danger of experiencing expanding water pressure due to environmental changes which are as a result of the fast ascent in temperatures (Niang; Ruppel; Abdrabo; Essel; Lennard; Padgham; Urquhart, 2014). The ever-growing population increases the demand for food supplies and worsens water-related problems (Parry, et al., 2015). Moreover, environmental change is expected to negatively affect rural food supplies in African countries and districts. This is on the grounds that yields from downpour took care of homesteads might be diminished by up to 50\% during droughts (Slegers, 2008; Parry, et al., 2015). Hunger and malnutrition are most likely to be more normal in Africa due to the change in climatic patterns. Most investigations found that Africa is among the weakest mainland, especially, with the reported environmental changes. Particularly, due to the law rate of transformation, limited access to recent agricultural technologies as well as the assortment of stressors (Schneider, et al., 2007; Niang, et al., 
2014). Some of the countries in Africa faces the greatest floods, and increased droughts as a result of climate change (Parry, et al., 2015).

The continuous rise of temperatures, and evaporation rate, contributes immensely to the loss of water in lakes, dams, and streams and the extinction of all aquatic life (Nwaerema, 2020). The loss of water, does not only affect human and animal life, but directly impede agricultural production. The agricultural sector depends on a number of farming input for production to occur. This includes water, fertilizers, sees or seedlings and other important farming inputs. However, water as a natural resource, remains paramount in agricultural production, both in crop and livestock production. Crop producers are faced with diminishing returns as a result of reduced yields, especially in the rain-fed farming. Moswentsi; Fanadzo; Ncube (2017) suggests that the adoption of water conservation strategies by farmers, especially, smallholder farmers will increase farming resilience. Some scholars, suggests that in the era of climate change, smallholder farmers have a number of adaptation strategies to choose from, depending on availability of resources and skills. These includes Climate-Smart Agriculture, Precise Agriculture, Digital Agriculture, Conservation Agriculture, and Water-Smart Agriculture.

A number of authors argue that the aforementioned adaptation strategies employed by farmers across the world assist to increase farming resilience. Literature on WaSA submits that WaSA aims to increase water resource utility for optimal agricultural production (Luo et al., 2017, Moswentsi et al., 2017; IICA, 2018). On the other hand, Amudson et al., (2015) submits that WaSA aims to conserve the readily available and accessible scare water resource. WaSA refers to an agricultural system or practice that focuses on irrigation water use efficiency. However, not much is known about WaSA as far as its applicability, the rate of adoption by farmers as well as perception and assertiveness of smallholder farmers on the impact and influence of WaSA in their agricultural businesses. It is noted by IICA (2018) that WaSA is a new concept and more research is yet to be conducted to uncover the applicability of WaSA in smallholder farming. Moreover, the impact of WaSA on irrigation water use efficiency as well as assessing the rate at which WaSA is adopted by farmers, particularly, smallholder farmers is yet to be researched. Therefore, the study attempted to examine Water-Smart agricultural practices employed by emerging farmers; to assess the perception of emerging farmers in the adoption of Water-Smart Agriculture; and to determine the adoption behavior of farmers towards Water-Smart Agriculture practices.

\section{Objectives of the study}

- To examine Water-Smart Agricultural practices employed by emerging farmers in the study area.

- To determine the adoption behaviour of farmers towards Water-Smart Agricultural practices.

\section{Methodology}

The study was conducted in the Chochocho (Dingledale) area of Bushbuckridge Local Municipality in Ehlanzeni District, which is adjacent to Mbombela Local Municipality in Mpumalanga, South Africa. The total area $5,46 \mathrm{~km}^{2}$, and has a total population of 4845 individuals, blacks $(99,5 \%)$, whites $(0.2 \%)$, Indians and coloreds with $0.1 \%$. The dominant languages spoken in the area includes: Xitsonga, Sepedi, Siswati, Sesotho and IsiZulu. 


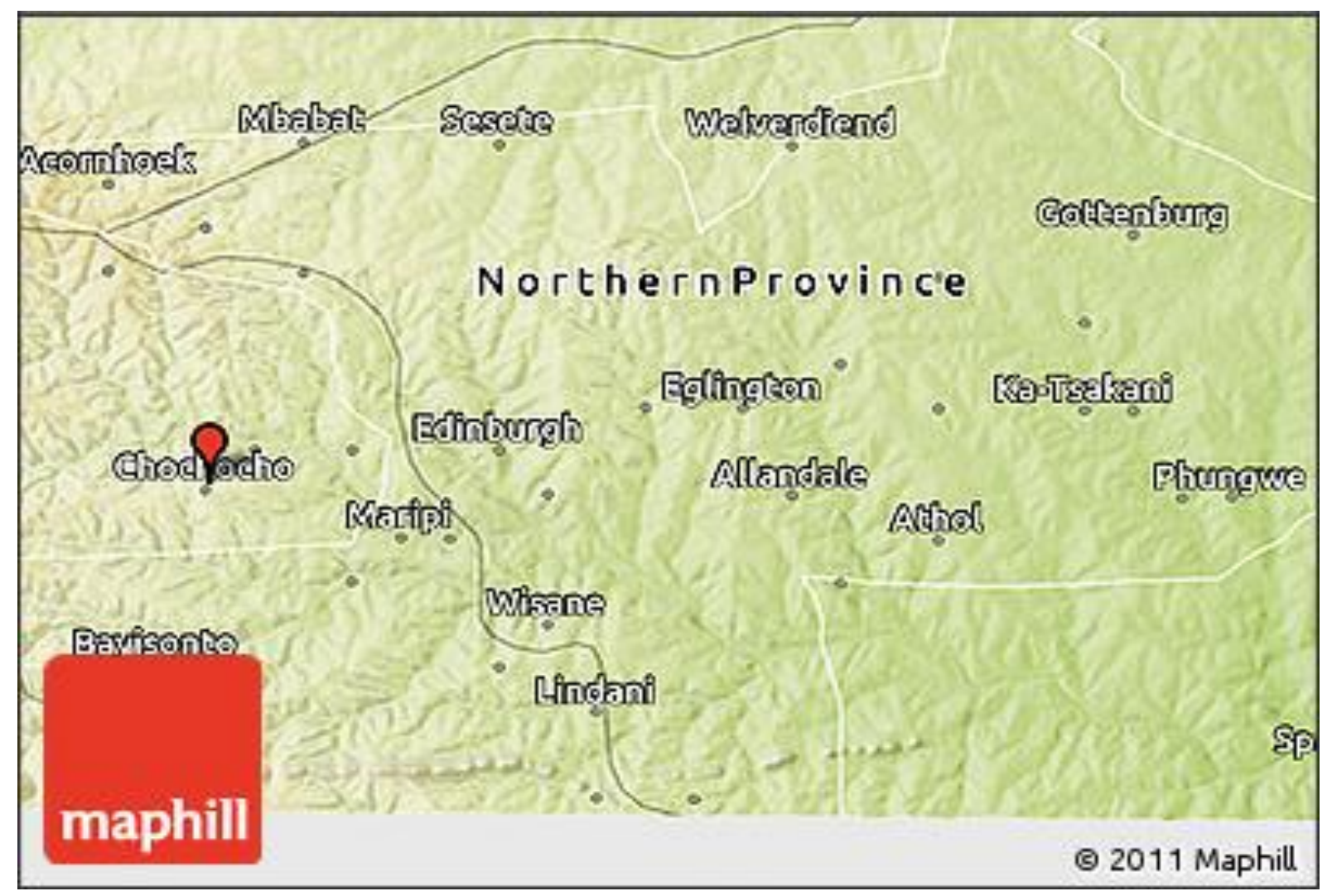

Figure 1: Map of Chochocho community

Source: Maphill (2013)

\section{Sampling Procedure and Data Collection Tools and Techniques}

The random sampling technique was employed with an indication that no special treatment of farmers in the sampled population. However, the likelihood of any farmer in the group being selected does not necessary depend on any other farmer in the population. This approach used, avoided gender bias and 261 participants were randomly sampled. Structured questionnaires were used to obtain information from farmers and was divided into two sections: the first part was on socio-economic demographics of the smallholder farmers while the second part was centered on adoption behaviour of farmers in the use of WaSA. Furthermore, focus group discussions were employed to understand crop production pattern and objectives as well as farming practices used. Other PRA tools such as transect walk, Venn diagram, trend and time analysis were employed to capture common crop production practices employed in the study area. Moreover, to obtain sample size, the Slovin's formula was employed and is reflected below:

$$
n=\frac{N}{1+N e^{2}}=\frac{750}{1+750(0.05)^{2}}=260.86=261
$$


$\mathrm{N}=$ sample size $(261)$

$\mathrm{e}=$ Margin of error $(0.05)$

$\mathrm{N}=$ Total population $(750)$

Method of Data Analysis

Descriptive statistics involving frequency, mean and percentages were used to analyze data collected, and to satisfy the first objective of the study. The adoption behavior of smallholder farmers of WaSA practices was analyzed using the multi-nominal logistic regression analysis.

\section{Logical framework and empirical model}

The hypothesis on the influence of the socio-economic characteristics of farmers on adoption behaviour was tested using the binary logistics regression. The Statistical Package for Social Sciences software (SPSS version 27) was used analyze the data collected for the study. Collected data was screened before captured into SPSS to ensure quality of primary data entry. The editing and highlighting of salient errors of omission in the computation of data and testing for missing values was also done. Multi-nominal regression was used to determine the relationship between selected demographic (independed or determinant) variables and the dependent variables. Moreover, the determinants of adoption of WaSA practices or otherwise, suggest individual direction to maximize utility because of rationality in behaviour. Multi-nominal regression model used to examine farmers' decision to adopt or not to adopt WaSA practices was as follows:

Where:

$\mathrm{Y}=$ Adopt WaSA (farmers adopt $=1,0=$ otherwise $)$

$\mathrm{X} 1-\mathrm{X} 6=$ independent variables illustrated as:

$\mathrm{X} 1=$ Age (years)

$\mathrm{X} 2=$ Level of education (literate $=1.0=$ otherwise)

$\mathrm{X} 3$ = Farm experience (indicated in years)

$\mathrm{X} 4$ = Farm size $($ size in ha)

$\mathrm{X} 5$ = Information support on WaSA (1= support, $0=$ otherwise $)$

$\mathrm{X} 6=$ Access to Extension $(\mathrm{Yes}=1,0=$ otherwise $)$

$\beta 0=$ constant

B1- $\beta 15=$ standardized partial regression coefficients

$\mu=$ error term 
The choice to adopt WaSA as a practice was presented as dependent variables with the assigned values $1-\mathrm{Pi}$, and if not $\mathrm{Pi}$. The table 1 , indicate the independent variables with a priori expectations as follows:

Age appears as a continuous variable and was stated in years, with the expectation that younger farmers may be inclined to undertakings and therefore are less likely to be risk averse as compared to the elderly farmers (Knowler and Bradshaw, 2007). Level of education was considered as dummy variable with the value of 1 if farmers are educated and 0 otherwise. Educated farmers may likely accept innovation easily as compared to uneducated farmer. Furthermore, educated farmers are disposed to well informed decisions that may improve adoption of WaSA practices. Therefore, the higher the level of education the higher the chances to adopt WaSA. Farm experience as a continuous variable was presented as the number of years a farmer remained in farming. The expectation is that farm experience will influence adoption decision making as more experienced farmers are disposed to informed decision making. Farmers access to support on the use of WaSA were measured by the capability to access assistance. The access to support was indicated as dummy variable, and a farmer with access to government support information takes the value of 1 or 0 otherwise. However, access to government support was expected to influence the decision of adopt WaSA practice. Farm size was prepared and measured in acres. Farmers with larger farm size shows potential for success and therefore, farm size is expected to influence adoption of WaSA. Extension services was regarded as dummy variable with the value of 1 , if farmer had contact with extension and 0 otherwise. Extension as a social capital helps in building trust, provides assistance, and share innovative information with farmers. It was assumed in this study that smallholder farmers with access to extension services are more likely to adopt WaSA practice in the area.

\section{Results and Discussions}

\section{Respondents' awareness of WaSA agricultural practices in the study area}

Findings reveals that (72.6\%) of all the smallholder farmers who participated in the survey were not familiar with WaSA practices and did not know that WaSA practices can be used on farm as means to conserve irrigation water. However, a small number (27.4\%) of the respondents were aware of WaSA practices and that they seldom employ it in their farms (figure 1). WaSA practices are connected to Climate-Smart Agriculture (CSA), as a result of the efficient water use management practices contributing also to the CSA goals of increasing crop productivity and farmer adaptation to the effects of climate change. The efficient use of water and irrigation management practices, and the minimizing of water quality impacts, calls for innovative training, retraining with robust extension activities in the study area. 


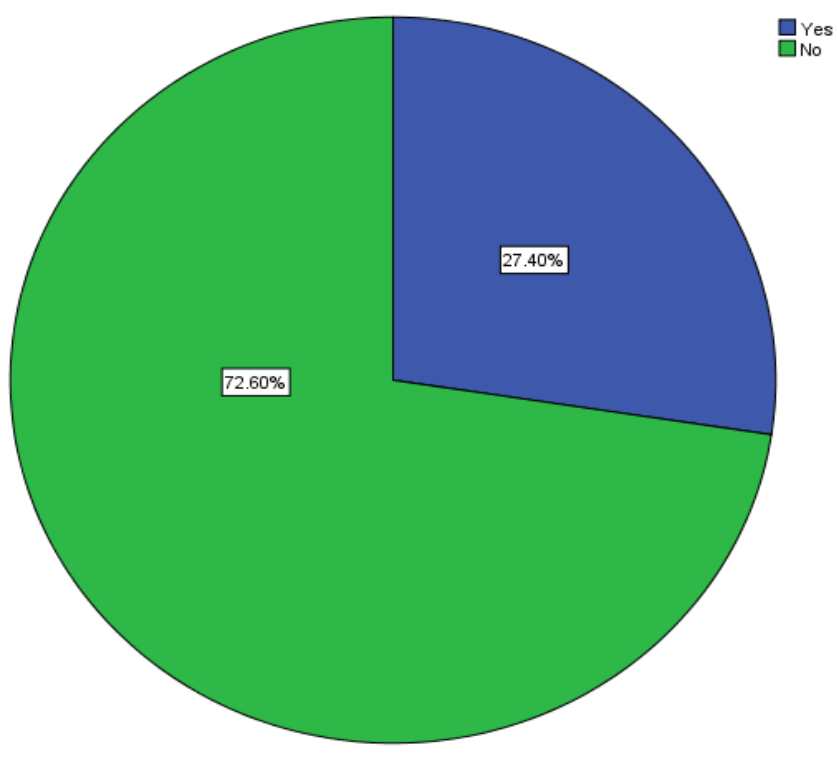

Figure 2: Respondents' awareness of WaSA practices in the study area

\section{WaSA practices used by respondents in the study area}

Findings as indicated in figure 2, show that $5.94 \%$ of the total of 219 smallholder farmers who participated in the study use crop rotation as a WaSA practice. Of the 219 smallholder farmers involved in the study, $3.20 \%$ use mulching and $18.26 \%$ use a combination of both crop rotation and mulching as WaSA practices. WaSA, is one of the key conservation practices for achieving a sustainable food production while decreasing hunger and poverty. Significantly, $72.60 \%$ respondents asserted that they do not use WaSA practices in their farms. This is therefore, concluded to result from the unawareness of the smallholder farmers about the WaSA. Almost $75 \%$ of the world's smallholder farmers depend on their farming practices for the generation of income and provision of food to them and their families (World Bank, 2013). Similarly, agricultural development and the consequent increase in farm incomes must be seen as one of the important ways to take smallholders farmer out of poverty. This is particularly significant as a result of previous studies predicting that by 2050 global agricultural production could sustainably increase by $60 \%$ to satisfy the food and fiber needs of an additional two billion people. Moreover, agricultural production should double in the Sub-Saharan African region to meet the growing demands for food (Alexandratos and Bruinsma, 2012). This increase must be understood under WaSA and climate change conditions, without necessarily compromising the natural resource endowment on which our food and depend. In this context, employing various types of WaSA can be used to sustainably increase agricultural productivity to facilitate enhanced agricultural development. 


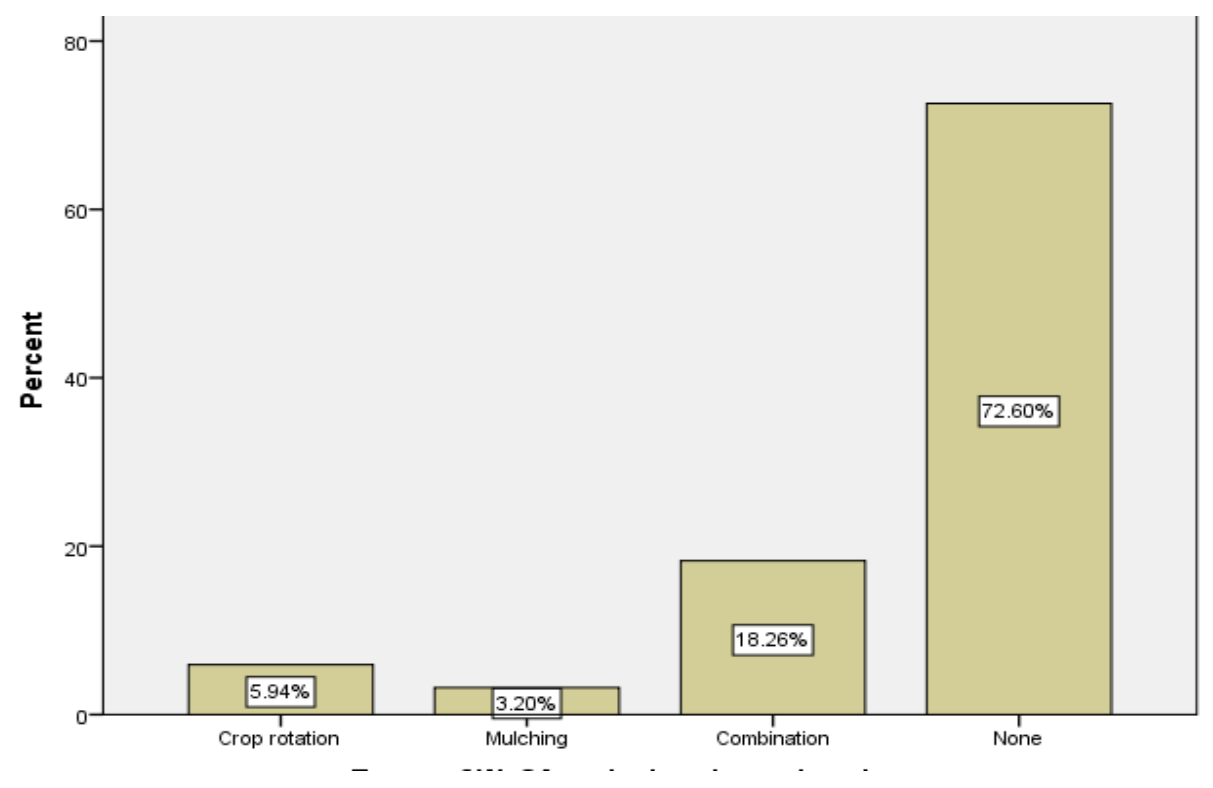

Figure 3: WaSA agricultural practices used by respondents in the study area

\section{Determinants of farmers' decisions to adopt Water Smart Agriculture}

Table 1, below, indicate the multi-nominal regression results with the independed variables employed in the determination of farmers' decisions to adopt or not to adopt WaSA. In models, with a categorical dependent variable, the computation of single R2 statistics that has all characteristics of R2 in any model is impossible. Hence, approximations are made instead, and therefore, this study adopted this technique. As indicated in table 1, the Pseudo R2 shows a summary of the proportion of variance of the dependent variable which is associated with the predictor (independent) variables. With Cox and Snell (0.319), McFadden (0.581) and Nagelkerke R2 of 0.659 result obtained, show that more of the variables were explained in the model and that the model fit the study (Nagelkerke,1991). In the model, five independent variables were positive and significant but negatively influence adoption of WaSA practice with the exception of farm experience.

The result reveals that age was significant with $p$-value of 0.039 but negatively $(\beta=-0.336)$ related to decision to adopt Water Smart practices for farming (table 1). This result implies that for every yearly increase in age of respondents there is 0.336 times decrease in the Log odds of decision to adopt WaSA practice. This result is consistent with the study of Lubisi et al., (2021), who found that age of farmers negatively influenced smallholder farmers' choice to adopt the use of ICT in Driekoppies, Mpumalanga Province. Farm size was significant and positively related to adoption of WaSA with a p-value $=0,000$ and $\beta=1.162$. This result suggests that for every unit increase in farm size of respondents, there is 1.162 times increase in the Log odds of adoption of WaSA, when all other variables are held constant. This result agrees with Agholor (2021) in his study on access to local markets and information, found that farm size was significant and positively related to the choice or decision to participate in local market in Clau- Clau, Mbombela. Government support show significant relationship but negatively influence adoption with $\mathrm{P}$-value $=0.041$ and $\beta=-0.663$. The implication of this finding is that for any support received by a farmer there is 0.663 times decrease in the Log odds of adoption of WaSA. 
The contact with extension service personnel recorded a significant relationship with P-value 0.001, but negatively related to adoption of WaSA. This result implies that for every unit increase in the number of contacts with extension services, there is 0.525 times decrease in the Log odds of adoption. It should be noted, however, that extension services increase the level of awareness and plays a vital role for information dissemination to farmers (Agholor and Nkosi, 2020; Nyangane and Juma, 2014). The level of education was positive and significant with a $p$-value $=0.000$ but negatively $(\beta=-3.574)$ influence the choice to adopt WaSA. This implies that holding all variables constant, for every increase in the level of education there is 3.574 decrease in the Log odds for adoption of water smart agriculture by respondents. The findings, however, is in contrary with the study of Ntshangase et al., (2018), found that education influences the adoption of conservation agriculture.

Table 1: Determinants of farmers' decision to adopt Water-Smart Agriculture

\begin{tabular}{lcccccccc}
\hline Parameter Estimates & & & & & & \\
\hline
\end{tabular}

Pseudo R2:

Cox and Snell $\quad .319$

Nagelkerke $\quad .659$

McFadden $\quad .581$

The asterisks $[0.01 * *$ and $0.00 * *]$ represent statistical significance at 0.05 and 0.1 levels respectively

\section{Conclusion}

The study aimed to examine Water-Smart Agriculture practices employed by smallholder farmers in the study area and to determine the adoption behavior of farmers towards Water-Smart Agriculture. The respondents were randomly sampled for the purpose of the study and this was done purposely to afford all the participants and equal chance of being sample. Structured questionnaires were used to gather information and were purposely divided into two sections, that is, 1 . The section to gather information about the socio-economic characteristics of the respondents and 2 . The section designed to ask questions on the use of WaSA practices by smallholder farmers in the study area. Descriptive 
statistics involving frequency, mean and percentages was employed to analyze the data. The adoption behavior of smallholder farmers was analyzed using the multinomial logistic regression analysis. The analysis of data for this study was done using the Statistical Package for Social Sciences software (SPSS version 27). Furthermore, independed variables for the study were: age, level of education, farm experience, farmland size, information support on WaSA and access to extension services. The determinants of smallholder farmers' adoption of WaSA practices or otherwise, suggests individual direction to maximize utility because of rationality in behaviour. Findings revealed that majority (72.6\%) of smallholder farmers who participated in the survey were not familiar with WaSA practices. The study found that age, farm size, government support, level of education, and contact with extension services were significant and positively related to the choice or decision to adopt WaSA. WaSA agricultural practices are connected to Climate Smart Agriculture (CSA) and the efficient water management contributes to CSA goals of increased productivity and adaptation. The efficient use of water and irrigation management practices, and the minimizing of water quality impacts, calls for innovative training, retraining with robust extension activities in the study area. WaSA is a key concept for achieving a sustainable food production while decreasing hunger and poverty, especially, in rural areas. Similarly, agricultural development and farm income maximization should be viewed as one of the important ways to help smallholders' farmers out of poverty. It is therefore, recommended that the relationship between smallholder farmers and their access to extension services be investigated to further uncover the impact of extension services in the adoption of WaSA practices and other practices to help farmers move towards Sustainable Agriculture. Researchers further recommend that government support to smallholder farmers be strengthened, especially, in the aspect of influencing farmers to adopt recent farming technologies, instead of just the provision of farm inputs.

\section{Acknowledgements}

The authors would like to appreciate the University of Mpumalanga for funding their attendance at the AGRICO 2021 Conference, as well as the ethical Clarence release for the purpose of this study.

Declaration of Interest Statement: The authors declare that they have no conflict of interest.

\section{References}

Agholor, A. I. (2021). Access to local agricultural markets and information for subsistence farmers in clau-clau mbombela, South Africa. Turkish Online Journal of Qualitative Inquiry, Vol. 12 (7), $8678-8690$.

Agholor, A. I., \& Gama, B. (2020). Perception on land reform in Reef, Nkomazi Distrcict Mpumalanga, South Africa. International Journal of Science and Research, Vol. 76 (10), 83 94. Doi: 10.21506/j.ponte.2020.10.6.

Agholor, A. I., \& Nkosi, M. (2020). Sustainable Water Conservation Practices and Challenges among Smallholder Farmers in Enyibe Ermelo Mpumalanga Province, South Africa. Journal of Agricultural Extension, Vol. 24 (2), 112 - 123. Doi: 10.4314/jae.v24i4.12.

Agricultural Statistics. (2008). Directorate: Agricultural Statistics of the National Department of Agriculture. Pretoria, South Africa. 
Ahmed Khan, Z., \& Nawaz, A. (2020). Impact of Climate Change Awareness on Climate Change Adaptions and Climate Change Adaptation Issues. Pakistan Journal of Agricultural Research, vol. 36 (3), 619 - 636. Doi: 10.17582/journal.pjar/2020/33.3.

Alexandratos, N., \& Bruinsma, J. (2012). World Agriculture Towards 2030/2050: The 2012 Review. Working Paper, No: 12 - 03. Agricultural Development Economics Division, FAO, United Nations, pages $1-147$.

Amundson, R., Berhe, A. A., Hopmans, J. W., Olson, C., Sztein, A. E., \& Sparks, D. L. (2015). Soil and Human Security in the 21st Century. Journal of Soil Science, Vol. 348 (6235), 647 - 655. Doi: $10.1126 /$ science.1261071.

Dey, A., \& Mukherjee, S. (2019). Conservation Agriculture: Future of Agriculture. Journal of Soil Sciences, Vol. 18 (3), 30 - 41.

FAO. (2013). FAO Climate Smart Agriculture .Sourcebook (online). Rome, Italy. Retrieved on the May 21, 2021. Accessed from http: //www.fao.org/docrep/018/i3325e/i3325e.

FAO. (2014). FAO success stories on climate-smart agriculture (online). Rome, Italy. Retrieved May 21, 2018, Accessed from http: //www.fao.org/3/a-i3817e.

Ghosh, A., Reja, M., Kanthal, S., Nalia, A., \& Nath, R. (2019). Climate Smart Agriculture. Journal of Environment and Ecology, Vol. 37 (4), 1221 - 122.

Greyling, J. (2015). A look at the Contribution of the Agricultural Sector to the South African Economy. Department of Agricultural Economics, Stellenbosch University, South Africa.

Inter-American Institute for Cooperation on Agriculture (IICA). (2018). Water-Smart-Agriculture (WaSA)-Brief. University of California, Davis, Inter-American Institute for Cooperation on Agriculture. California, USA.

IPCC. (2007). Impacts, Adoptation and Vulneability. Contribution of Working Group II to the Fourth Assessment Report of the Intergovergovernmental panel on Climate Change. In Summary for policymakers, in climate change. Cambridge, Cambridge University Press, United Kingdoms.

Kelly, J. (2019). Sciencing: The top 10 causes of global warming. Retrieved on the $24^{\text {th }}$ May 2021. Accessed from http: //www.sciencing.com/top-10-causes-of-global-warming.

Knowler, D., \& Bradshaw, B. (2007). Farmers' Adoption of Conservation Agriculture: A Review Synthesis of Recent Research. Journal, of Food Policy, Vol. 32 (1), 25 - 48. Doi: org/10.1016/j.foodpol.2006.01.003.

Lacetera, N. (2019). Impact of Climate Change on Animal Health and Welfare. Animal Frontiers, Vol. 9 (1), 26 - 31. Doi: 10.1093/af/vfy030.

Lubisi, P., Agholor, A., \& Ogujiuba, K. (2021). Climate Threat and Alternatives for Farming in Driekoppies, Mpumalanga, South Africa. Annals of the Romanian Society for Cell Biology, Vol. 25 (6), $10311-10321$.

Luo, J., Wyatt, J., van der Weerden, J., Thomas, S., de Klein, C., Li, Y., Rollo, M., Lindsey, S., Ledgard, S., Li, J., Ding, W., Qin, S., Zhang, N., Bolan, N., Kirkham, N., Bai, Z., Ma, L., Zhang, X., Wang, H., Liu, H., Rys, G. (2017). Potential Hotspot Areas of Nitrous Oxide 
Emissions from Grazed Poatoral Diary Farm Systems. Advances in Agronomy, Vol. 14 (5), $205-268$.

Maphill, M. G. (2013). Retrieved on the 22 ${ }^{\text {nd }}$ April 2021. Accessed from http: //www.maphill.com.south-africa/northern-province/mapulaneng-o/chochocho/3Dmaps/physical-map/free.

Mekonnen, M., \& Hoekstra, A. (2016). Four billion people facing sever water scarcity. Science Advances , Vol. 2 (1), 1 - 6. Doi: 10.1126/sciadv.1500323.

Moswentsi, G., Fanadzo, M., \& Ncube, B. (2017). Cropping Sytems and Agronomic Management Practices in Smallholder Farmes in South Africa: Constraints, Challengies and Opportuninties. Journal of Agronomy, Vol.16 (2), 51 - 64.

Nagelkerke, N. J. (1991). A note on a General Definition of the Coefficient of Determination. Biometrika, Vol. 78 (3), 691-692.

Niang, I. O., Ruppel, M., Abdrabo, A., Essel, C., Lennard, J., Padgham, \& P. Urquhart, 2. (2014). Africa. In: Climate Change 2014. In V. Barros, C. Field, M. M. D.J. Dokken, \& A. L. E.S. Kissel (Eds.), Impacts, Adaptation, and Vulnerability. Part B: Regional Aspects. Contribution of Working Group. Cambridge, Cambridge University Press, United Kingdom.

Ntshangase, N., Muroyiwa, B., \& Sibanda, M. (2018). Farmers' Perceptions and Factors Influencing the Adoption of No-Till conservation Agriculture by Small-Scale Farmers in Zashuke, KwaZulu-Natali Province. Journal of Sustainability, Vol. 2 (10), 555 - 564.

Nwaerema, P., (2020). Impact of Climate Change on Insects,Pest, Diseases and Animal Biodiversity. International Journal of Environmental Sciences and Natural Resources, Vol. 23 (5), 1 - 3. Doi: 10.19080/IJESNR.2020.23.556123.

Nyangane, W., \& Juma, O. (2014). Impact of improved farm technologies on yeild: The case of improved maize variables and inorganic fertilizer in Kenya. Enviromental development. Discussion paper series. Narobi, Kenya.

Parry, M., Canziani. O., Palutikof, P., Van der Linden, P, \& Hanson, C. (2015). Climate Change 2007: Impacts, Adaptation and Vulnerability. IPCC WGII Fourth Assessment Report, pages 1 $-22$.

Prakash, S., \& Srivastava, S. (2019). Impact of Climate Change on Biodiversity: An Overview. International Journal of Biological Innovations, Vol. 1 (1), 60 - 65. Doi: 10.46505/IJBI.2019.1205.

Schneider, S. S., Semenov, A., Patwardhan, I., Burton, C., Magadza, M., Oppenheimer, A., Smith, A. (2007). Assessing key vulnerabilities and the risk from climate change. Climate Change 2007. In O. C. M.L. Parry (Ed.), Impacts, Adaptation and Vulnerability. Contribution of Working Group II to the Fourth Assessment Report of the Intergovernmental Panel on Climate Change. Cambridge, Cambridge University Press, United Kingdom.

Sithole, M. Z., \& Agholor, A. I. (2021). Delineation and Dimension of Deforestation. IntechOpen, Doi: 10.5772/intechopen.98290. Retrieved on the $25^{\text {th }}$ June 2021. Accessed from: https://www.intechopen.com/online-first/76948. 
Slegers, M. (2008). Exploring farmers' perceptions of drought in Tanzania and Ethiopia. Wagening: Doctoral Thesis Wagening University. ISBN: 978-908585-240-7.

Stillman, D. (2014). Nationl Aeronauti and Space Administration( NASA): What is climate change. (S. May, Editor) Retrieved on the 17 August 2017. Accessed from http: //www.nasa.gov.what is climate change.

Uddin, M., Bokelmann, W., \& Entsminger, J. (2014). Factors Affecting Farmers' Adaptation Strategies to Environmental Degradation and Climate Change Effects: A Farm Level Study in Bangladesh. . Climate, 2, 223-241.10.3390/cli2040223.

The World Bank (WB). (2013). Annual Report 2013. Washington D.C, USA. 